Mémoire.

\title{
HYPERENDEMIC ONCHOCERCIASIS IN THE TARABA RIVER VALLEY OF GONGOLA STATE (OLD ADAMAWA PROVINCE), NIGERIA
}

\author{
O. B. AKOGUN, C. O. E. ONWULIRI
}

\begin{abstract}
SUMMARY
A survey of the prevalence of onchocerciasis was carried out in the Taraba river valley, Nigeria where Simulium damnosum s. 1. is known to breed but about which no epidemiological data exists. Skin biopsies taken from 2,876 persons in 14 communities were examined for the microfilariae of Onchocerca volvulus. $100 \%$ infection rate was recorded in one of the communities, five other

communities had prevalence rates between $81.0 \%$ and $94.7 \%$. Three communities had infection rates between $44.8 \%$ and $69.1 \%$. The mean microfilarial density in all the communities was 64.7 with a range between 3.2 and 167.6. The present findings indicate that the Taraba river valley may be one of the worst onchocerciasis zones in Nigeria.
\end{abstract}

RÉsumé : Onchocerciasis hyperendémique de la vallée de la rivière Taraba de l'État de Gongola (Old Adamawa, Province) Nigeria.

Une enquête sur la fréquence de l'Onchocercose a été faite dans la vallée de la rivière Taraba (au Nigeria) où la présence de Simulium damnosum $s$. l. était connue mais sans données épidémiologiques. Des biopsies de peau faites sur 2876 personnes de 14 communautés ont été examinées pour la recherche des microfilaires d'Onchocerca volvulus. Un taux d'infection de $100 \%$ a été établi dans l'une des communautés tandis que cinq autres com- munautés ont un taux de fréquence compris entre $81,0 \%$ et $94,8 \%$. Trois communautés ont des taux d'infection compris entre $44,8 \%$ et $69,1 \%$. La densité moyenne des microfilaridermies dans toutes les communautés est de 64,7, variant entre 3,2 et 167,6. Les données actuelles montrent que la vallée de la rivière Taraba paraît être l'une des pires zones d'Onchocercose au Nigeria.

\section{INTRODUCTION}

Onchocerciasis is perhaps the most well studied filarial disease in Nigeria (Crosskey, 1956, 1957, 1958; Edungbola et al., 1983; Ufomadu et al., 1988). About seven million Nigerians are estimated to be infected while another fortytwo million are at risk of infection. Every year new foci of onchocerciasis transmission are discovered thus revealing that its distribution is far more extensive than has been hitherto assumed. Accordingly, various levels of endemicity have been reported in different parts of the country since Dyce-Sharp (1926) published his first report. The most notable foci of transmission in the central and northern states of Nigeria have been identified as the Abuja zone (Crosskey and Crosskey, 1959); the Galma river valley (Crosskey, 1981), river Assob (Onwuliri et al., 1987), the Hawal valley at Borno state (Bradley, 1972) and Kwande local council area of Benue state (Gemade and Dipeolu, 1983), the Jarawa valley of Plateau state (Nwoke et al., 1989). The entire area of the old Adamawa province (now Gongola state) seemed to have been over-looked in these

Applied Entomology and Parasitology Unit, Departement of Zoology, P. M. B. 2084, Jos, Nigeria.

Present address: B. Akogun, Box 10121, University P. O., Jos, Nigeria.

Accepté le: $1^{\text {er }}$ octobre 1990. surveys. There are therefore no published reports on onchocerciasis in Gongola state although Duke et al. (1966) and Crosskey (1981), on the basis of flies caught during a casual prospection at Bali had suggested that the Taraba river valley may be one of the worst foci of onchocerciasis in Nigeria. The present paper reports the preliminary findings of ongoing studies on the transmission of $O$. volvulus along the Taraba river valley.

\section{MATERIALS AND METHODS}

\section{THE STUdy AREA}

The Taraba is one of the most important rivers in Gongola state of Nigeria. The river takes source from the high attitude of the Alantika hills along the Nigeria-Cameroon border in the south eastern part of the state $\left(11^{\circ} 30^{\prime}-11^{\circ} 43^{\prime} \mathrm{E} ; 70^{\circ} 10^{\prime}-8^{\circ}\right.$ $15^{\prime} \mathrm{N}$ ) and stretches north-westwards covering a distance of $265 \mathrm{~km}$ before entering the Benue river. Throughout the first two-thirds of its length the river flows over a pre-Cambrian rock basement from very high attitude descending at the rate of about $0.6 \mathrm{~m}$ per $\mathrm{km}$. Many suitable rapids for blackfly breeding are thus created. The study reported here covers the first $130 \mathrm{~km}$ of the river and an area of about $1,300 \mathrm{~km}^{2}$ of the valley from headwaters at Mayoselbe (fig. 1). The area is well drained and the mean annual rainfall exceeds $1,397 \mathrm{~mm}$ with about eight months of active rainfall (March-October). The Jibawa are the major ethnic group (about $70 \%$ ) that inhabit the area. The local population live in small 


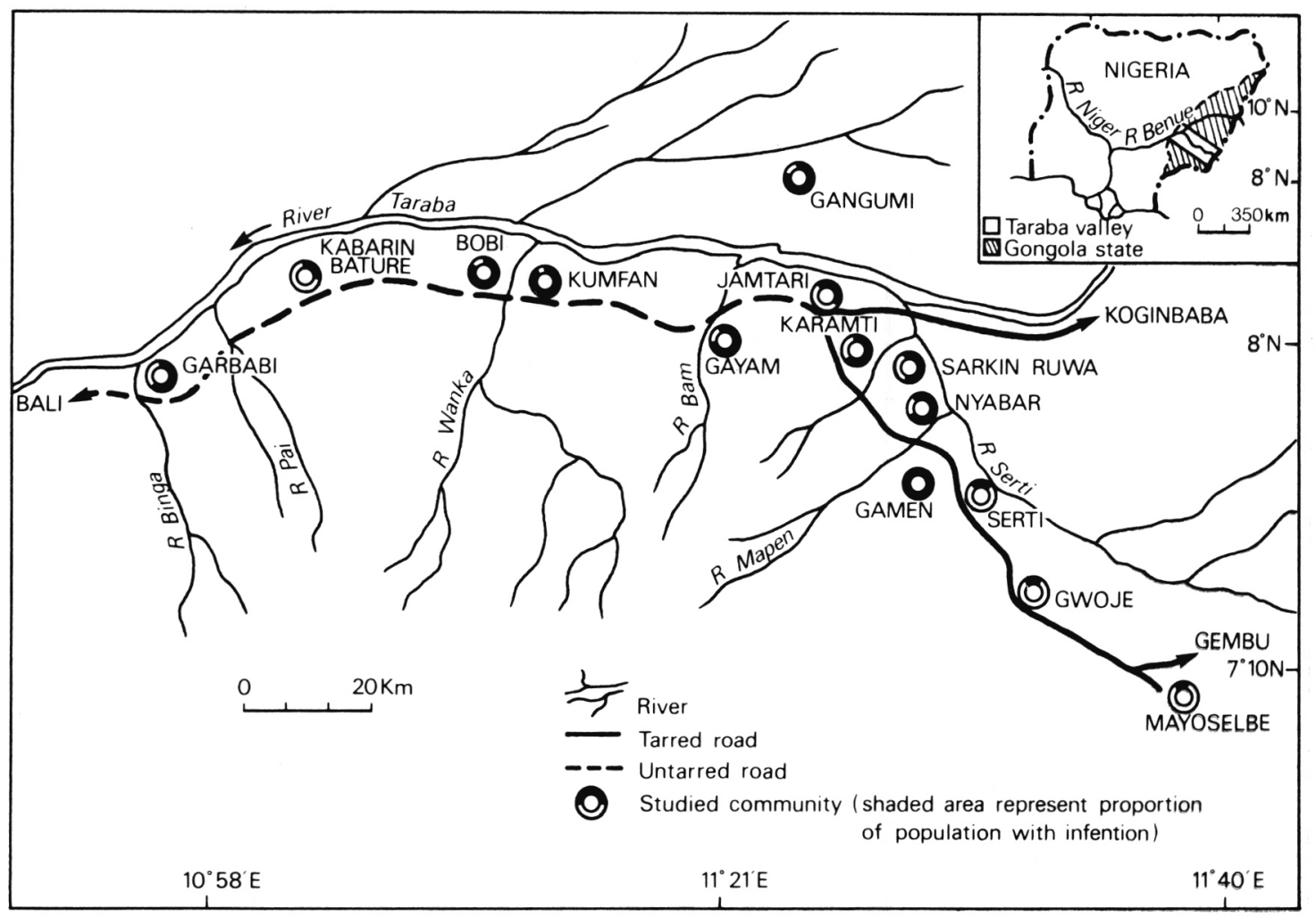

Fig. 1. - Taraba River Valley.

clusters of farming communities which are located at either side of and in close proximity to the river. Fourteen communities located along the only road that passes through the area were selected for study.

Information on each individual was obtained for age, sex, occupation and ethnic grouping and recorded on a standard epidemiological field form.

\section{PARASITOLOGICAL TECHNIQUES}

All persons aged 18 months and above were invited for examination. With the assistance of the district head and the local authorities the people were asssembled at the community headman's compound and all those that showed up were examined. The procedures of the onchocerciasis control Programme (OCP) in West Africa which have been described by Prost et al. (1975) and WHO (1976) were closely followed.

Two skinsnips were taken from either side of the iliac crest using the German-made Holth type corneoscleral punch with $1.5 \mathrm{~mm}$ bite after cleaning the site with cotton swabs moistened in $70 \%$ ethanol. Each skin snip was placed in polystrene microtitration plates with U-shaped wells containing $0.2 \mathrm{ml}$ of isotonic saline. The wells of completely filled plates were covered with adhesive tape to prevent evaporation and spilling of contents during transportation (Schulz-Key, 1978). The skin snips were observed within twenty-four hours using a binocular compound microscope ( $\times 50$ magnification). The microfilariae of $O$. volvulus were identified by their morphology and their number counted and recorded on the individual's from.

\section{RESULT}

2,876 persons were examined and 1,406 or $48,9 \%$ of them were $O$. volvulus positive. Infection rates among the
14 communities differed widely (Friedman's 2-way Anova by ranks, $\mathrm{P}<0.05)$. The sporadic level of infection recorded at the headwaters in Mayoselbe and Gwoje contrasts sharply with the hyperendemicity in the mid-Taraba valley. The entire population of those examined in Gamen were infected while $94.7 \%$ were positive in Bobi. Altogether six communities had infection rates beyond 80 per cent. Three communities were mesoendemic, while the others were either hypoendemic or sporadic (table I). The minimum age of infection varied between 18 months and 5 years.

Comparison of infection rates in age groups and sex did not show any remarkable difference up to age 19 years when male infection rates seem to rise above that of female (table II). The differences between sexes were well marked in communities where less than $50 \%$ of the inhabitants were infected but are negligible in hyperendemic communities.

The prevalence of onchocerciasis was not uniform among the various ethnic groups (Chi-square test $=410.9, \mathrm{P}<0.01$ ). The Jibawa were the most affected ethnic group (72.6\%) while the Tiv were the least infected $(17.0 \%)$. Infection with $O$. volvulus also differed between occupations. $76.7 \%$ of the farmers were infected but only $18.6 \%$ of traders and artisans had infection (table III).

Mean microfilarial density per skin snip varied between communities. As expected mean microfilarial density and infection rate were closely related $(r=0.92, \mathrm{P}<0.001)$. 
TABLE I. - Prevalence and intensity of $\mathrm{O}$. volvulus infection in each community.

\begin{tabular}{lcrr} 
Community & No. exam. & No. $(\%)+v e$ & $\begin{array}{c}\text { Mean microfilarial density } \\
\text { (mfd) }\end{array}$ \\
\hline Mayoselbe & 320 & $27(8.4)$ & 6.3 \\
Gwoje & 130 & $10(7.7)$ & 3.2 \\
Serti & 413 & $72(17.4)$ & 14.9 \\
Gamen & 60 & $60(100.0)$ & 167.6 \\
Nyabar & 84 & $68(81.0)$ & 86,2 \\
Sarkinruwa & 135 & $73(54.1)$ & 51.4 \\
Karamti & 165 & $114(69.1)$ & 70.2 \\
Jamtari & 426 & $191(44.8)$ & 49.6 \\
Gayam & 192 & $252(85.4)$ & 97.4 \\
Ganyumi & 304 & $54(94.7)$ & 81.7 \\
Bobi & 57 & $43(81.1)$ & 135.6 \\
Kumfan & 53 & $33(28.7)$ & 97.3 \\
Kabarinbature & 115 & $245(57.8)$ & 30.3 \\
Garbabi & 420 & $1,406(48.9)$ & 51.9 \\
$\quad$ Total & 2,876 & & 67.4 \\
\hline
\end{tabular}

TABLE II. - Prevalence and intensity of $\mathrm{O}$. volvulus Microfilariae by age and sex.

\begin{tabular}{|c|c|c|c|c|c|c|c|c|c|}
\hline \multirow[b]{2}{*}{$\begin{array}{c}\text { Age group } \\
\text { (years) }\end{array}$} & \multicolumn{3}{|c|}{ Male infected } & \multicolumn{3}{|c|}{ Female infected } & \multicolumn{3}{|c|}{ Total infected } \\
\hline & $\begin{array}{c}\text { No. } \\
\text { exam. }\end{array}$ & No. $(\%)$ & $M f d$ & $\begin{array}{l}\text { No. } \\
\text { exam. }\end{array}$ & No. $(\%)$ & $M f d$ & $\begin{array}{l}\text { No. } \\
\text { exam. }\end{array}$ & No. $(\%)$ & $M f d$ \\
\hline$<5$ & 148 & $29(19.6)$ & 8.3 & 162 & $32(19.8)$ & 7.7 & 310 & $61(19.7)$ & 8.0 \\
\hline $5-9$ & 330 & $106(32.1)$ & 28.5 & 288 & $85(29.5)$ & 16.1 & 618 & $191(30.5)$ & 22.3 \\
\hline $10-14$ & 273 & $123(45.1)$ & 45.3 & 163 & $55(33.7)$ & 40.8 & 436 & $178(40.8)$ & 43.1 \\
\hline $15-19$ & 120 & $74(61.7)$ & 57.5 & 116 & $63(54.3)$ & 50.5 & 236 & $137(58.1)$ & 54.0 \\
\hline $20-29$ & 207 & $147(71.0)$ & 87.3 & 225 & $123(54.7)$ & 59.3 & 432 & $270(62.5)$ & 73.3 \\
\hline $30-39$ & 188 & $137(72.9)$ & 106.1 & 207 & $139(67.1)$ & 75.1 & 395 & $276(69.9)$ & 90.6 \\
\hline $40-49$ & 140 & $81(57.9)$ & 115.1 & 78 & $49(62.8)$ & 151.7 & 218 & $130(59.6)$ & 133.7 \\
\hline $50-59$ & 78 & $50(64.1)$ & 106.2 & 45 & $32(71.1)$ & 81.0 & 123 & $82(66.7)$ & 93.6 \\
\hline$\geqslant 60$ & 78 & $60(76.9)$ & 99.3 & 30 & $21(70.0)$ & 77.4 & 108 & $81(75.0)$ & 88.4 \\
\hline Total & 1,562 & $807(51.7)$ & 72.7 & 1,314 & $599(45.0)$ & 62.2 & 2,876 & $1,406(48,9)$ & 67.4 \\
\hline
\end{tabular}

Communities with high disease prevalence had an equally high microfilarial density (fig. 2). The highest microfilarial

TABLE III. - Distribution of infection by ethnic grouping and occupation.

\begin{tabular}{|c|c|c|c|}
\hline \multirow[b]{2}{*}{ a) Ethnic group: } & \multicolumn{2}{|c|}{ No. O. volvulus positive } & \multirow[t]{2}{*}{$M f d$} \\
\hline & exam. & No. $(\%)$ & \\
\hline Jibawa & 1,125 & $817(72.6)$ & 136.7 \\
\hline Hausa/Fulani & 422 & $167(39.6)$ & 60.3 \\
\hline Chamba & 367 & $198(54.0)$ & 102.0 \\
\hline Tiv & 370 & $63(17.0)$ & 29.5 \\
\hline Mumuye & 57 & $21(36.8)$ & 66.0 \\
\hline Wurbo & 50 & $11(22.0)$ & 41.0 \\
\hline Others & 485 & $129(26.6)$ & 36.3 \\
\hline Total & 2,876 & $1,406(48.9)$ & 67.4 \\
\hline \multicolumn{4}{|l|}{ b) Occupation } \\
\hline Farmers & 1,202 & $922(76.7)$ & 189.5 \\
\hline Civil servants & 128 & $24(18.8)$ & 23.7 \\
\hline Students & 244 & $98(40.2)$ & 69.0 \\
\hline Trader/artisans & 247 & $46(18.6)$ & 16.3 \\
\hline Others & 1,055 & $316(30.0)$ & 38.5 \\
\hline Total & 2,876 & $1,406(48.9)$ & 67.4 \\
\hline
\end{tabular}

densities were recorded in Gamen and Bobi which also had the highest infection rates. Gwoje and Mayoselbe had the least prevalence of disease as well as the lowest microfilarial densities. The mean microfilarial density showed a similar pattern in both sexes (fig. 3). Like prevalence of $O$. volvulus, the microfilarial density seems to increase with age except at age 40-50 year group when a slight decrease in prevalence was observed in both sexes. The microfilarial density similarly declined between age 50-60 year group. The close association between prevalence of disease and microfilarial load was also observed among ethnic groups $(r=0.99, \mathrm{P}<0.01)$.

\section{DISCUSSION}

The findings of this study have confirmed that the Taraba river valley is one of the hyperendemic onchocerciasis zones in west Africa and is probably the worst yet in Nigeria. Previous studies did not record such high prevalence rates of onchocerciasis in other parts of Nigeria (Crosskey and Crosskey, 1959; Udonsi, 1986; Onwuliri et al., 1987). 


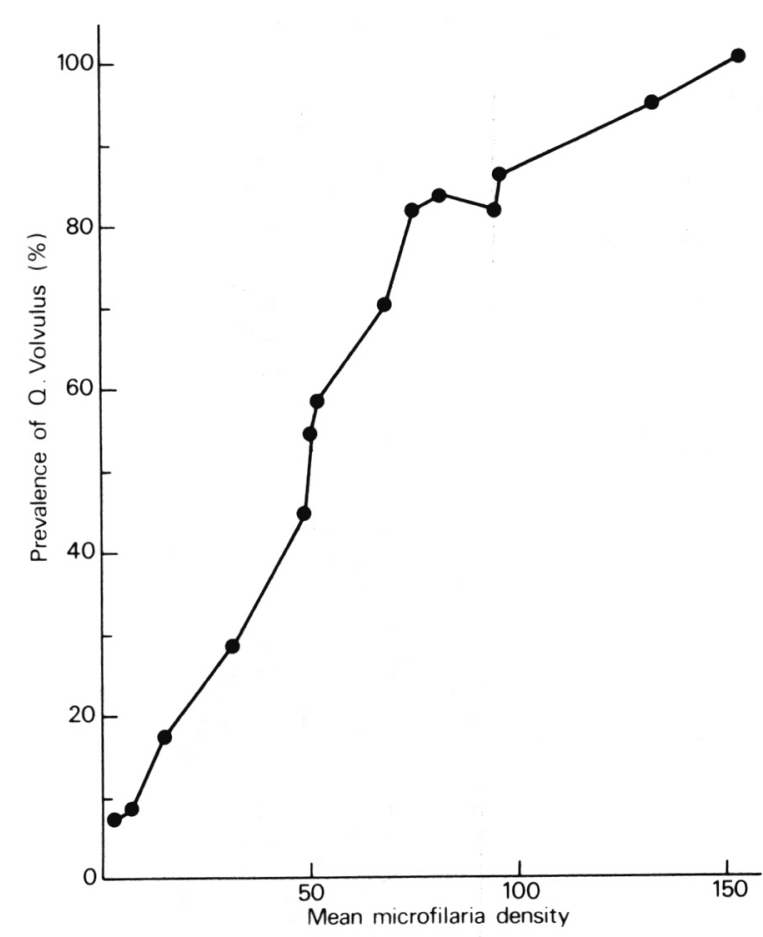

FIG. 2. - Prévalence and mfd in each community.


FIG. 3. - Pattern of distribution of onchocerciasis and microfilarial load by age and sex.

The relatively lower prevalence rates in Serti, Sarkinruwa, Karamti and Garbabi are not surprising. Observations made in West Africa showed that isolated low preva- lence rates may occur in the midst of hyperendemicity (OCP, 1973). Serti, the local council area headquarter is semi-urban with a fair proportion of unstable population of artisans and traders. Garbabi on the other hand is located near Bali an urban settlement. Majority of the population in Garbabi are Hausa-fulani, traders and artisans. It is likely that reduced exposure to Simulium bites may be the reason for the relatively low prevalence of disease in the communities. Kabarin-bature is a 5-year old settlement although interviews with the district head reveal that it had been abandoned twice in the past sixty years.

Observations show that active $O$. volvulus transmission takes place in Kabarinbature as well as in all communities between Serti and Garbabi. In the studied communities almost every activity is capable of bringing the individual in contact with the vector fly. Men and women worked on the fields and live in the same communities where flybites could be considerably high; flybites within compounds was noticed in Gamen and Gayam. This could explain the similarity in infection rates in both sexes during the first twenty years of age. Anderson et al. (1976) and Crosskey and Crosskey (1959) also observed that initial infections were similar for both sexes up to a particular age before differences occur. In hyperendemic communities, infection once acquired is rarely lost but continues to build up as a result of superinfections. This may explain why onchocerciasis prevalence and microfilarial density increase with age and are closely related. This may also explain the high infection rate among farmers whose occupation brings them in continuous contact with vectorflies. The close association between the number of microfilarial positive individuals and the mean density of microfilaria in a community tends to suggest that it may not be necessary in extensive baseline surveys to attempt to assess the density of micro-filaria by counting. A community's infection rate is usually indicative of its mean microfilarial density.

Initially the cut-off age for parasitological examination was 3 years but when active flybites within community were observed in Sarkin-ruwa the cut-off age was reduced to 18 months. The isolation of $O$. volvulus microfilaria from several 18-month olds seems to further support the suggestion that the Taraba is probably Nigeria's worst onchocerciasis zone; previous studies in other foci did not report prevalence rates at such an early age (Udonsi, 1986; Onwuliri et al., 1987). It seems that individuals probably received their first infective Simulium damnosum bites during the first few months of life. This is very likely: babies were often laid out under tree shades with little protection from flybites while the adults worked further afield. A baby may also receive its first infective bite while riding on the mother's back or even, as in Gayam, a bite may be received within the family compound. More detailed clinical and entomological studies on exposure and transmission patterns will be reported in a further publication. However, 
present findings show that extensive surveys of all likely Simulium breeding sites in Nigeria as suggested by Crosskey $(1979,1981)$ is very necessary before a comprehensive map of onchocerciasis prevalence for Nigeria can be drawn and before the current national onchocerciasis control programme can succeed.

Acknowledgement. - We acknowledge the assistance of the Gongola state Ministry of Health and the Onchocerciasis Field Team. We are especially grateful to Mr Hickson Hellandendu, Dr OUMAR, and Dr Musa of the state epidemiological unit for support. Our thanks also go to the chief of Gashaka, the secretary and the health department of the Gashaka local council.

\section{RÉFÉRENCES}

Anderson J., Fuglsang H., de C. Marshall T. F. : Studies on onchocerciasis in the United Gameroon Republic II. A 4-year followup of 6 Rainforest and 6 Sudan-Savanna villages. Trans. $R$. Soc. Trop. Med. Hyg., 1976, 70, 362-373.

Bradley A. K. : The effect of disease on rural economy, social structure and settlement: a case study of onchocerciasis in the Hawal valley, Nigeria. Unpublished WHO document. WHO/ONCHO/72.93, 1972, Geneva.

Crosskey R. W. : A review of Simulium damnosum s. l. and human onchocerciasis in Nigeria with special reference to Geographical distribution and the development of Nigerian National Control Campaign. Trop. Med. Parasitol., 1981, 32, 2-16.

Crosskey R. W. : An appraisal of current knowledge of Simulium damnosum s. 1. in the Federal Republic of Nigeria in relation to the development of an onchocerciasis control Campaign. Unpublished WHO document. WHO/ONCHO, 1979, 150.

Crosskey R. W., Crosskey M. E. : A quantitative survey of onchocerciasis in persons under twenty years of age in an endemic area of Northern Nigeria. Ann. Trop. Med. Parasitol., 1959, 53, 10-29.

Crosskey R. W. : The body weight in unfed Simulium damnosum Theobald, and its relation to the time of biting, the fatbody and age. Ann. Trop. Med. Parasitol., 1958, 52, 149-157.

Crosskey R. W. : Further observations on infection of Simulium damnosum on infection of Simulium damnosum with Onchocerca volvulus in northern Nigeria. Trans. R. Soc. Trop. Med. Hyg., 1957, 51, 541-548.
Crosskey R. W. : The distribution of Simulium damnosum Theobald in northern Nigeria. Trans. R. Soc. Trop. Med. Hyg., 1956, 50, 379-392.

Duke B. O. L., Lewis D. J., Moore P. J. : Transmission of forest and Sudan savanna strains of Onchocerca volvulus from Cameroon by Simulium damnosum from various west African bioclimatic zones. Ann. Trop. Med. Parasitol., 1966, 60, 318336.

Dyce-Sharp N. A. : A contribution to the study of Onchocerca volvulus Leuckart, with some observations on its prevalence in Nigeria. Trans. Soc. Trop. Med. Hyg., 1926, 19, 373-388.

Edungbola L. D., Oni G. A., Aiyedun B. A. : Babana Parasitic Diseases Project I: the study of Onchocercal endemicity based on the prevalence of "leopard skin". Trans. R. Soc. Trop. Med. Hyg., 1983, 77, 303-309.

Gemade E. I., Dipeolu O. O. : Onchocerciasis in the Benue State of Nigeria II. Prevalence of disease among the Tivs living in the Kwande local government area. Ann. Trop. Med. Parasitol., 1983, 77, 513-516.

Nwoke B. E. B., Onwuliri C. O. E., Shiwaku K. Ufomadu G. O., Tada I., Takahashi H. : Endemic onchocerciasis on the Jarawa valley area of Plateau state, Nigeria. Jpn. J. Trop. Med. Hyg., $1989,17,205-211$.

Onchocerciasis Control Programme : Epidemiological aspects of onchocerciasis in the volta river basin area. Unpublished document. OCP 73.1 Annex iv-1, 1973.

Onwuliri C. O., Nwoke B. E., Lawal I. A., Iwuala M. O. : Onchocerciasis in Plateau state of Nigeria II. The prevalence among residents around the Assob river area. Ann. Trop. Med. Parasitol., 1987, 81, 49-52.

Prost A., Thylefors B., Pairault C. : Methods of mass epidemiological evaluation of onchocerciasis their utilization in a vector control programme. Unpublished WHO document. WHO/ $\mathrm{ONCHO} / \mathrm{WP} / 75.14,1975$.

Udonsi J. K. : The status of human filariasis in relation to clinical signs in endemic areas of the Niger Delta. Ann. Trop. Med. Parasitol., 1986, 80, 425-432.

Ufomadu G. O., Eno R. O., Akoh J. I., Takahashi H., Uchida A., Hayakawa H., Watanabe M., Sato Y., Ekejindu G. O. C., Onwuliri C. O. E., Emeh J. K. : Evaluation of skin biopsies from different body regions of onchocerciasis patients in central Nigeria. Acta Trop., 1988, 45, 257-261.

World Health Organization : Epidemiology of Onchocerciasis Technical Report Series. 597, 1876, Geneva p. 94. 